\title{
Natural White Pinkish Fairness Advertisement
}

\section{Ignacia Ardelia Petrina}

English Department, Faculty of Languages and Literature, Petra Christian University, Siwalankerto 121-131, Surabaya 60236, INDONESIA

e-mail: ardelia.petrina@gmail.com

\begin{abstract}
This study observes the perceived meanings towards perceived meanings stated by people with different skin colors towards a skin whitening product advertisement. The subjects for this research are people with dark and fair skin. The writer used the theory of perceived meaning, semiosis, representation, interpretation, and lightskinned beauty in Indonesia to analyze the perceived meanings. The study used descriptive qualitative approach to reveal the perceived meanings of the respondents in a systematic way. From this study, it was found that skin color was one of the factors that affects the process of perceived meaning. Dark skin respondents produced perceived meanings that dark skin was beautiful. Meanwhile, fair skin respondents agreed that fair skin equaled beauty. However, they also produced similar perceived meanings due to the similar culture and common stereotype.
\end{abstract}

Key words: Advertisement, Verbal Expressions, Visual Expressions, Perceived Meaning.

\section{INTRODUCTION}

Products and services are sold through businesses that are differentiated by their brand identities. Brand identity is communicated to the consumers by advertising. That is why advertisement becomes one of the promotion tools that is commonly used by most companies. It is obvious that advertisement plays important roles in introducing and promoting products or services. According to Percy $(2005$, p.4), advertisement as a tool to turn people or mass toward a product or service by providing a positive feeling information that goes well beyond simply calling people's attention into it. Advertisements portray the images and ideas into product and services, just as the meanings of products and services are presented in verbal and visual expression.

Visual and verbal expressions play an important role in delivering messages from advertisement to the customers. Visual expressions can be in a form of picture. Pictures hold a vital part in advertisement since it is the first thing that attracts the customers to see an advertisement. Pictures contain many messages that are not typed. Therefore, it can be interpreted differently by each reader. Other than that, an advertisement also contains language as verbal expressions. Language in an advertisement can appear in the form of narration, caption, text, and slogan. Language functions as the message carrier in the advertisement. From language, the readers can get the message of the advertisement. However, language can also be interpreted differently by each customer due to the differencea in background knowledge.

For this research, the writer is interested to find out how the viewers perceive the meaning of the advertisement. Perceived meaning is the interpretation of sign; more or less clarified meaning (Tomaselli, 1996). In interpreting an advertisement, the readers can have different perceived meaning. Each respondent might have different meaning based on their background knowledge. Therefore, there might be a chance that the perceived meanings produced by the readers are different from the intended meaning from the advertiser. The cause of the difference varies in many things, from age, education, social class, gender, etc. These factors affect the way the readers comprehend and interpret certain discourse.

The writer chooses to analyze skin whitening product advertisement. A dramatic growth of skin whitening and lightening products has occurred in Asian markets. According to www.cosmetics design-asia.com (2013), skin lightening has long been a trend in Asia and is set to continue to boost the global market in the next five years. The advertisement that is analyzed is Olay Natural White Pinkish Fairness advertisement. Olay is a cosmetic brand originated from South Africa. This brand has expanded its product around the world, including some Asian countries like Indonesia, Philippine, Malaysia, and Thailand. The latest product that was launched in Indonesia is Olay Natural 
White Pinkish Fairness. In this research, the writer involves ten young women in their twenties to help her enrich the research. The respondents are divided into group of dark skin and fair skin. The writer obtains to find out whether skin color will affect the way the respondents perceive the meaning of the same advertisement.

\section{METHOD}

In this research, the writer used descriptive qualitative approach. The reason why the writer used qualitative research was because the writer aimed to reveal the perceived meaning of people with dark and fair skin towards Olay Natural White Pinkish Fairness advertisement. This research dealt with individual interpretation to the objects of analysis, namely: verbal and visual expressions in the advertisement. Furthermore, descriptive qualitative approach is the most suitable approach for this research as it describes the meaning of qualitative material in a systematic way (Schreier, 2012, p.1).

The data of this analysis were verbal and visual expressions from the advertisement. Verbal expressions were in the form of captions or narrations and visual expressions were in the form of pictures, color, or gaze. Totally, there are nine scenes on the advertisement. However, the writer limited the scenes that were analyzed into five scenes. The criteria in choosing the specific scenes were based on the connotation. The writer chose specific verbal and visual expressions that had connotation in order to find out how the respondents would perceive the meaning. Therefore, the writer could gather adequate data later on for the analysis.

In this research, the writer chose ten female respondents because it is a cosmetic product that is specifically designed for women who aim to have fair and glowing skin with pinkish and radiant glow. The writer involved young adult respondents in the age of 20 to 25 years as they were considered as the main target of Olay Natural White Pinkish Fairness. Other than that, the writer chose respondents who were familiar with whitening products so that they had sufficient knowledge about whitening products. However, it was not obligatory for the respondents to have experience in using whitening products. The respondents were divided into two categories: groups of people with dark skin and fair skin. The writer decided to divide them into two groups to see whether skin color affect the way people perceived the meaning of a skin whitening product advertisement. The categories also helped to discover the differences or similarities of the perceived meaning towards the same skin whitening product produced by people with different skin color.

The data used in this research were collected from a semi-structured interview. This type of interview allows the writer to develop an understanding of the topic of interest without being limited by the questions in Appendix 2. In that way, the writer could explore the respondents more. In asking the questions, the writer showed the specific captions along with the pictures / scenes that came along with the captions.

\section{ANALYSIS AND FINDINGS}

In order to answer the research question, the writer analyzed three things:

- The perceived meaning stated by people with dark skin towards the verbal and visual expressions of the skin whitening product advertisement.

- The perceived meaning stated by people with fair skin towards the verbal and visual expressions of the skin whitening product advertisement.

- The differences or similarities of the perceived meanings stated by people with fair and dark skin viewers towards the verbal and visual expressions of the skin whitening product advertisement.

\section{The Analysis of Perceived Meanings Produced by Respondents with Dark Skin}

In this part, writer started the analysis on the darsk skin respondents' perceived meanings towards the verbal and visual data. 


\section{Dark Skin Respondents' Perceived Meanings of the Verbal Data Table 2: Dark Skin Respondents Verbal Data Perceived Meanings Summary}

\section{Dark Skin Respondents' Perceived Meanings}

- Beauty should be natural and realistic. Beauty is not being perfect because it is unrealistic. Flaws or weaknesses are also part of beauty.

- Beauty can also be supported by internal factor such as facial expressions and confidence, also external factor such as technology, lighting, and clothes

- Beauty is authentic Indonesia because Indonesian women's characteristics do not belong in other standard of beauty.

- Beauty is exotic because it is praised by Americans or Europeans as sexy and attractive.

- Natural skin is genuine skin without the using of any products. The use of makeup or skin product in any dose is considered as unnatural.

- Natural skin is genuine skin with minimal use of makeup. The function of makeup is to support and improve natural skin.

- Whitening products cannot whiten skin. It cannot whiten skin no matter how long the usage is.

- Whitening products might whiten skin with regular use. It might whiten but it takes a long time with no instant effect.

- Whitening products can temporarily whiten skin. It can whiten skin for a certain period of time after that the skin color will get back to the original color.

- Men prefer women with fair skin. Women with fair skin have advantage from the label that fair equals beauty.

- Men do not prefer women with fair skin. Skin colour is not the only factor in choosing a spouse. It also depends on the character, personality, and behaviour of women.

The respondents with dark skin did not relate the words shown along with the pictures. They preferred to relate the verbal data with their own experiences and culture. The writer found out most of them did not agree with the idea that fair skin equaled beauty. They perceived beauty as something which was not only about physical appearance such as face or skin color. Beauty can also be supported by internal factors such as facial expressions and confidence, also external factors such as technology, lighting, and clothes (OOTD - outfit of the day).

They also did not agree about the idea of other types of beauty such as Korean beauty or exotic beauty to be the beauty standard of Indonesian. They prefer authentic Indonesian and exotic skin. The reason is because Indonesian women with mostly tanned skin do not have the characteristic of fair skin like Korean. The writer saw that they wanted to show that Indonesian women were superior by breaking the common stereotypes of making people outside Indonesia as the standard of beauty.

They produced 2 perceived meanings regarding the definition of natural skin. . The first perceived meaning is natural skin is genuine skin without the use of any makeup. According to them, the use of makeup is considered as unnatural. The reason is because makeup more or less will change the natural features of the natural skin. The second perceived meaning is natural skin is genuine skin with minimal use of makeup. On this part, they considered the use of makeup as something that is acceptable as long as the function is to enhance the beauty features on the natural skin. They did not agree if the use of makeup is to change any features of the skin, such as whiten or darken skin. In other words, the function of makeup is to support and improve natural skin.

However, it goes different in terms of romance and social media representation. Most of the dark respondents agreed that fair skin women were more superior on those fields because of the label given to them. Related to the skin whitening product, most of the dark skin respondents did not believe that it could perfectly whiten skin. They had the experience of using whitening skin products 
but did not get the whitening effect. Because of that, they come to the conclusion that they should start to accept their skin colour. Furthermore, they become more confident with their dark skin.

\section{Dark Skin Respondents' Perceived Meanings of the Visual Data}

Table 2: Dark Skin Respondents' Visual Data Perceived Meanings Summary

Dark Skin Respondents
- $\quad$ Beauty is more about the structure of the face rather than skin colour. Beauty is not
having fair skin or dark skin. The structure of the face is what makes a woman beautiful.
- Mixed-blood girl is beautiful. Mixed-blood face is good looking.
- Milk can whiten skin. The main reason is because the respondents have been familiar
- - Ingredients are not really convincing enough to whiten skin. Misinterpretation towards
the visual of the product affects the respondents in seeing the use of the product.
- Beauty is about her face her and fair skin. Pretty face and fair skin make a woman
prominent.
The girl is pretty because of the structure of her face not the skin colour. The girl is
naturally beautiful with her cute face and smile so skin colour does not really affect
her beauty.
The girl is mediocre. She is not ugly but she is not that really pretty. The cute face is
what makes her more attractive.
The girl is not beautiful because she looks unrealistic. The skin colour of the girl is too
fair.
- Having fairer skin does not drastically make women prettier. Their face before and
after having fair skin is exactly the same so it does not make sense to say the girls are
prettier.
- Having fairer skin makes them look unrealistic. The skin colour transformation looks
unrealistic
- Having fairer skin makes women prettier and more attractive. In visual, the girls look
prettier in fair and glowing skin.
Women with fair skin more prominent rather than dark skin on social media. Women
with fair skin are the centre of the attention.
attention on social media. People look unconfident when they do weird poses and facial
expressions.

On perceiving visual data, the respondents were relating each picture to their daily life, experiences, and culture. They related the pictures with physical role such as: definition of beauty, skin colour transformation, and visual on social media. They also related it with emotional roles such as: skin colour affects confidence, self presentation on social media. The writer concluded that the respondents really emphasized on the message that beauty had nothing to deal with skin colour. That message was presented on the ideas that beauty was more about face structure.

Regarding the product and its ingredients, they only concerned about milk out of two main ingredients of the product, which were milk and France rose. Their main reason was because they have been familiar with the benefit of milk for whiten skin. They get used to see a lot of whitening products using milk as their main ingredients.

As a result of their perceived meaning about beautu and face structure, they argued that skin color transformation from dark to fair did not make the women in the advertisement prettier. According to them, the girls before having fair skin were already pretty. So, having fair skin did not change anything. They also agreed that the girls looked more confident rather than prettier. It could 
be seen towards their poses and facial expressions. Before, they looked unconfident because they did not want to show their face. They tried to hide it with silly poses and facial expressions.

However, the opposite perceived meaning was produced regarding the relation between skin color and social media representation. The dark skin respondents stated that people were more attracted to fair skin girl due to the common stereotype that has been there on the society. They agreed that fair skin women were more prominent which resulted on the receiving of more likes, followers, and attention on social media.

\section{The Analysis of Perceived Meanings Produced by Respondents with Fair Skin}

In this part, writer started the analysis on the darsk skin respondents' perceived meanings towards the verbal and visual data.

\section{Fair Skin Respondents' Perceived Meanings of the Verbal Data}

\section{Table 3: Fair Skin Respondents' Verbal Data Perceived Meanings Summary}

\begin{tabular}{|c|}
\hline Fair Skiı \\
\hline $\begin{array}{l}\text { - Beauty should be fair. Having fair skin makes people more prominent, especially around } \\
\text { people with darker skin colour. } \\
\text { - Beauty equals perfection from every aspect, such as skin, hair, facial expressions, and } \\
\text { clothes. } \\
\text { - Beauty is about confidence. Confidence enhances all of the beauty in a woman. } \\
\text { - Beauty should be authentic Indonesian. Indonesian women do not have any similar } \\
\text { physical characteristic with others beauty, such as Korean. } \\
\text { Beauty should follow the latest trend. Korean is the current beauty standard of } \\
\text { Indonesian due to the increase in global popularity of Korean cultures. } \\
\text { - Natural skin is genuine skin. The use of any products that change the genuine skin colour } \\
\text { is considered as unnatural. } \\
\text { - Natural skin is skin that looks realistic. The use of makeup is still acceptable. Makeup } \\
\text { functions to support the natural beauty. } \\
\text { - Whitening product can instantly whiten skin. The perceived meaning is truly from the } \\
\text { advertisement with no impact from other aspects. } \\
\text { - Whitening product cannot give instant effect. To whiten skin is a sustainable process } \\
\text { - Whitening product which gives instant whitening effect is dangerous. The ingredients } \\
\text { of the product might be harsh chemical. } \\
\text { Men prefer women with fair skin. Fair skin women are more attractive rather than dark } \\
\text { skin women. } \\
\text { Men prefer women with fair skin. Fair skin women looks like they have high hygience } \\
\text { in a sense that they can take care of themselves. } \\
\text { Not all men prefer women with fair skin. It depends on each man preference. }\end{array}$ \\
\hline
\end{tabular}

The respondents with fair skin did not relate the words and the picture shown along with the pictures. In perceiving the meaning of specific captions, they related it with their knowledge and real life experience. They agreed that Korean is the beauty standard of Indonesian women because it is the latest popular trend. From their answers, it can be seen that they agree with the idea that fair skin equals beauty. They might not say it explicitly that fair skin is beautiful. Still, they always mention fair skin and relate it with beauty on their answer. They mentioned that fair skin women look spotless and attractive. That is the reason they believed men preferred women with fair skin. The writer also found interesting thing that the fair skin respondents still wanted fairer skin because they wanted to be more attractive. 


\section{Fair Skin Respondents' Perceived Meanings of the Visual Data}

\section{Table 4: Fair Skin Respondents' Visual Data Perceived Meanings Summary}

\begin{tabular}{l} 
Fair Skin Respondents \\
\hline - The prettiest girl is the girl in the middle. Having fair skin make women more \\
prominent, especially around people with darker skin. \\
- The prettiest girl is the girl on the left. Beauty has no relation with skin colour. \\
the visual. The viewers are convinced that it can whiten skin because of the content of \\
the milk. \\
- The product is more suitable as lotion because of the dominant visual that represents \\
milk. Milk is more familiar as the ingredients of lotion rather than skin whitening \\
product. \\
- The girl is pretty because of her fair skin and also supported by great confidence and \\
happy facial expressions. \\
- The girls look more attractive in visual with fairer skin. Having fair skin makes women \\
prettier because they look neater. \\
- gonfidence and facial expression make women prettier. Having fairer skin does not \\
- Women with fair skin are more attractive on the photos. That results in receiving more \\
attention on social media. \\
The skin colour transformation does not affect the amount of attention that the photo \\
gets. The main star is always going to be the fair skin girl.
\end{tabular}

Most of the respondents are still consistent with the idea that fair skin equals beauty. In perceiving the meaning, the respondents relate the specific picture with their background knowledge which mostly consists of common stereotype. In this case, common stereotype that fair skin equals beauty strongly affect the way the respondents perceived the meaning. They stated that fair skin made women more prominent rather than people with dark skin. That gives benefit in social media representation because fair skin women get more attention from people in the forms of likes, attention, and followers. Other than that, the writer found that this group also concerned about confidence. They believed confidence enhances someone's beauty.

\section{Similarities and Differences between Dark and Fair Skin Respondents' Perceived Meanings}

The writer extended her research to find similarities and differences between dark skin and fair skin respondents' perceived meanings. The writer saw that skin colour affected the way the respondents perceived the meaning of Olay Natural White Pinkish Fairness. There are some similarities but also differences in the way the respondents perceived the meaning of specific captions and pictures from the advertisement.

There are some similarities of the perceived meanings produced by dark and fair skin respondents that the writer wants to point out. The first similarity is regarding the perceived meaning towards the definition of beauty. Most of the respondents of both groups agree that beauty consists of internal and external factors. In this case, internal factor is the appearance of someone, such as face, skin colour, confidence, and facial expressions. Meanwhile, external factors can be in the form of technology, makeup, lighting, and clothes. It needs the collaboration of internal factors and external factors to form someone's beauty.

The second similarity that the writer found is regarding the definition of natural skin. Both of the groups produced two similar perceived meanings. The first perceived meaning is natural skin is genuine skin without the use of any makeup. In this case, genuine skin is skin that has no impacts from any skin products or makeup. According to them, the use of makeup is considered as unnatural. The second perceived meaning is natural skin is genuine skin with minimal use of makeup. On this part, they considered the use of makeup as something that is acceptable as long as the function is to enhance the beauty features on the natural skin. 
The third similarity is regarding the perceived meanings towards the skin colour transformation of the dark women. Most of the respondents of both groups state that having fairer skin does not make women prettier or more attractive. The first reason is because beauty is more about face structure rather than skin colour. The second reason is great confidence and happy facial expressions are what make the women prettier.

The fourth similarity that the writer found is regarding the perceived meaning towards men's preference on fair skin women. More than half of the respondents got the perceived meaning which men preferred women with fair skin. The reasons vary from individual preference to the world's beauty standard. However, the respondents more concerned about the influence of the world in affecting men's preference on women.

Last but not least, the fifth similarity that the writer found is regarding the perceived meanings towards the relation of skin colour and social media behaviour. All of the respondents agreed with the statement that fair skin women receive more attention on social media rather than dark skin women. Fair skin women will always be the main star on the social media that grab people's attention.

Other than that, there are also differences. The first difference is regarding the perceived meanings towards the beauty standard of Indonesia. Dark skin respondents argued that the beauty standard of Indonesian should be exotic or tanned skin. On the other hand, most of the fair skin respondents chose Korean as the beauty standard of Indonesian. Their main reason is because beauty should follow the latest trend.

However, there are also respondents who argued that the beauty standard of Indonesia was authentic Indonesian. The reason is because the characteristics of Indonesian women do not belong on other types of beauty, such as Korean beauty or American beauty. For example the latest trend is Korean beauty. Korean beauty emphasizes on having fair and flawless glass skin. Most of Indonesian women that have dark skin do not have those characteristic. It goes the same as other types of beauty. According to them, Indonesian women do not have to fit in on other beauty standard. Otherwise, Indonesian women should start to enhance their own beauty.

The second difference that the writer wants to point out is regarding the perceived meanings towards the definition of beauty. Dark skin respondents had the perceived meaning that beauty was about face structure. Based on their opinion, people should judge beauty from face structure rather than skin colour. In this case, face structure is including face shape, features of the face such as eyes, nose, lips, and cheeks, and also facial expressions. The contrast perceived meaning comes from the fair skin respondents. They considered beauty as having fair skin. They argued that fair skin enhanced the beauty of a woman.

The third difference is regarding the perceived meanings towards the ingredients of the product related to the function to whiten skin. Dark skin respondents got the perceived meaning that whitening products could not whiten skin. The first reason is their personal experiences. According to them, they never see the whitening effect from the products even after a long term usage. Another reason is whitening effect from the products is only temporary. On the other hand, the fair skin respondents had the perceived meaning that whitening products could whiten skin. Most of them got that perceived meaning from the milk ingredient of the product that is shown on the specific captions and pictures. Milk is indeed being emphasized throughout the advertisement. It can be seen from the dominant colour of white on the visual.

\section{CONCLUSION}

The writer concluded that her research has revealed that skin colour could indeed affect the process of perceived meaning. Each group emphasized on different thing which could affect their perceived meaning. In this case, the writer thinks that dark skin respondents emphasize on the idea that dark skin is also beautiful. They wanted to break the stereotype which says beauty is about having fair skin. Meanwhile, the fair skin respondents emphasized on the idea that beauty indeed was equal fair skin. They related fair skin with attractiveness, social attention, better romance, and better representation on social media. However, common stereotype from the world and their culture still affect the respondents on the process of perceiving meaning. It shows on the part where both of the groups agreed that fair skin women received more attention on social media and men preferred women with fair skin. In giving those perceived meanings, the respondents related it with the reality 
that happens. Furthermore, the reality is constructed by the stereotype on the society. In conclusion, skin colour indeed affects the process of perceived meaning but in some cases, common stereotype still takes a role in affecting the respondents' perceived meaning.

\section{REFERENCES}

Chandler, D. (2007). Semiotics: The Basic 2nd ed. London.

Danesi, M. (2004). Semiosis, Representation, and Interpretation. In M. Danesi, Messages, Signs, and Meanings: A Basic Textbook in Semiotics and Communication (p. 16). Toronto, Canada: Canadian Scholar Press Inc.

McDougall, A. (2013, June 3). Retrieved 2018, from Cosmetic Design-Asia: https://www.cosmeticsdesign-asia.com/Article/2013/06/04/Skin-lightening-trend-in-Asiaboosts-global-market

Olay Indonesia. (2018, June 25). BARU! Olay Natural White Pinkish Fairness [Video file]. Retrieved from https://www.youtube.com/watch?v=I0-bneqgOQo

Percy, L. \& Elliott, R. (2005). Strategic Advertising Management. Oxford University Press.

Schreier, M. (2012). Qualitative Content and Analysis in Practice. Los Angeles: SAGE Publications, Ltd.

Teer-Tomaselli, Ruth (1996) 'DEBI Does Democracy: Recollecting Democratic Voter Education in the Electronic Media Prior to the South African Elections', in

George E. Marcus (ed.) Connected Engagements with the Media, pp. 377-421. Chicago and London: Chicago University Press. 